VITTI, M.C.D.; KLUGE, R.A.; YAMAMOTTO, L.K.; JACOMINO, A.P. Comportamento de beterrabas minimamente processadas em diferentes espessuras de corte. Horticultura Brasileira, Brasília, v. 21, n. 4, p. 623-626, outubro-dezembro 2003.

\title{
Comportamento da beterraba minimamente processada em diferentes espessuras de corte
}

\author{
Maria Carolina D. Vitti ${ }^{1,2}$; Ricardo Alfredo Kluge ${ }^{1,3}$; Liane K. Yamamotto ${ }^{1,4}$; Angelo Pedro Jacomino ${ }^{1,3}$ \\ ${ }^{1}$ ESALQ/USP. C. Postal 9, 13418-900 Piracicaba-SP; ${ }^{2}$ Bolsista CAPES; ${ }^{3}$ Bolsista CNPq; ${ }^{4}$ Bolsista de Iniciação Científica FAPESP; E- \\ mail: mcdvitti@esalq.usp.br
}

\section{RESUMO}

Avaliou-se a qualidade de beterraba minimamente processada com diferentes espessuras de corte. As raízes foram processadas nas espessuras de 2; 5 e $8 \mathrm{~mm}$. Após o preparo, foram acondicionadas em bandejas de poliestireno expandido e armazenadas a $5^{\circ} \mathrm{C}$ durante 10 dias. O delineamento experimental foi inteiramente casualizado em esquema fatorial $(3 \times 4)$. A cada 2 dias foram avaliados o teor de sólidos solúveis totais, a perda de massa, a coloração, a aparência, os teores de betacianina e de betaxantina e a taxa respiratória. $\mathrm{O}$ teor de sólidos solúveis totais foi maior no corte de $8 \mathrm{~mm}$, durante o período de armazenamento. Não houve diferença estatística entre os tratamentos em relação à coloração, à taxa respiratória e aos teores de betacianina e betaxantina. Pelos resultados obtidos, conclui-se que beterraba minimamente processada mantém boa qualidade para consumo por até 6 dias de armazenamento, independente do tipo de corte.

Palavras-chave: Beta vulgaris L., processamento mínimo, respiração, pigmentos

\begin{abstract}
Quality of minimally processed beet roots in different cut thickness

The quality of minimally processed beet roots with different cut thickness was evaluted. The roots were processed with 2; 5 and 8 mm thickness: After the preparation, the cut beets were conditioned in expanded polystyrene trays and stored at $5^{\circ} \mathrm{C}$ during 10 days. The experimental design was completely randomized in factorial arrangement. Every 2 days, the minimally processed roots were evaluated for total soluble solids contents, weight loss, coloration, appearance, betacyanin and betaxanthin content and respiratory rate. The total soluble solid content was higher for beets cut with $8 \mathrm{~mm}$ thickness. There was no statistic difference among the treatments in relation to coloration, betacyanin and betaxanthin contents and respiratory rate. Good quality of minimally processed beet roots can be maintained until the $6^{\text {th }}$ day of storage, independent of the cutting thickness.
\end{abstract}

Keywords: Beta vulgaris L., fresh-cut, respiration, pigments.

(Recebido para publicação em 25 de junho de 2002 e aceito em 12 de agosto de 2003)

A beterraba pertence à família Chenopodiaceae na qual a parte comestível é a raiz tuberosa. Esta hortaliça tem coloração vermelhoarroxeada devido à presença dos pigmentos betalaínas.

As betalaínas são compostos semelhantes às antocianinas e flavonóides. Foram denominadas incorretamente, na bibliografia antiga, por antocianinas que continham nitrogênio. Encontram-se presentes somente em 10 famílias da ordem Centrospermae. São pigmentos hidrossolúveis e estão divididas em duas classes: betacianina (responsável pela coloração avermelhada) e betaxantina (responsável pela coloração amarelada), caracterizando a coloração típica das raízes de beterraba (Fenena, 1995).

O processamento mínimo inclui operações de seleção, lavagem, descascamento e corte, visando obter um produto fresco e conveniente para o preparo e consumo (Burns, 1995). A durabilidade deste tipo de produto é ex- tremamente baixa se comparada ao produto inteiro, considerando que nas superfícies do corte, as células e a membrana celular são destruídas e ocorre alteração no metabolismo celular. Esta alteração no metabolismo, que inclui aumento na respiração e produção de etileno, resulta em redução drástica na vida pós-colheita do produto pré-processado. De acordo com Brecht (1995), quanto maior a gravidade da injúria nos tecidos, maior é a velocidade de deterioração do produto minimamente processado. Assim, é de se esperar que diferentes espessuras de corte promovam diferentes respostas quanto a qualidade e capacidade de conservação dos produtos minimamente processados.

A beterraba tem apresentado grande expansão no mercado de minimamente processados. Entretanto, tem sido observada elevada perda de qualidade em função da descoloração da superfície das raízes minimamente processadas e da elevada desidratação. Os processos de lavagem e enxague, realizados após o corte do produto, têm favorecido a perda dos pigmentos de betacianina e betaxantina.

Verificou-se no presente trabalho o efeito de diferentes espessuras de corte sobre o comportamento pós-colheita da beterraba minimamente processada.

\section{MATERIAL E MÉTODOS}

As raízes tuberosas, cv. Early Wonder, foram obtidas de um produtor da região de Piracicaba. As raízes foram selecionadas quanto a firmeza e ausência de danos mecânicos e infecção fúngica. Posteriormente foram prélavadas em água corrente com o objetivo de retirar as impurezas vindas do campo e colocadas em câmara fria a $10^{\circ} \mathrm{C}$ para depois serem minimamente processadas.

O produto foi descascado mecanicamente por descascadora industrial (Shymsen) com disco abrasivo e imerso 
em água resfriada $\left(5^{\circ} \mathrm{C}\right)$ por 2 minutos. A função desta imersão em água resfriada é retirar o calor de campo das raízes, reduzindo portanto a atividade metabólica do produto. A seguir as raízes foram submetidas à etapa de corte em forma de retalhos. Utilizou-se uma processadora (Robot Coupe) com disco de espessura de $2 ; 5$ e $8 \mathrm{~mm}$, constituindo os tratamentos. Após o corte, o material foi tratado por 6 minutos em água clorada (200 ppm de cloro ativo), com o objetivo de reduzir riscos de contaminação, e enxaguado por 1 minuto (em água com 3 ppm de cloro ativo) para a retirada do excesso de cloro. Em seguida, foram centrifugadas em centrífuga doméstica (ARNO) durante 1 minuto para a retirada do excesso de umidade presente no produto, com velocidade constante equivalente a $800 \mathrm{x} g$.

Todos os tratamentos foram acondicionados em bandejas de poliestireno expandido ( $180 \mathrm{~g}$ de produto por bandeja), nas dimensões 14×20 cm de largura e comprimento, respectivamente, envolvidas por filme de policloreto de vinila (PVC), com 14 micras de espessura e armazenados a $5 \pm 1^{\circ} \mathrm{C}$ e $85 \pm 5 \%$ UR.

O período de armazenamento foi de 10 dias, sendo que as avaliações foram realizadas a cada 2 dias. As variáveis analisadas foram: a) teor de sólidos solúveis totais: por leitura direta em refratômetro digital (Atago), utilizandose uma gota de raiz centrifugada em centrifuga doméstica. Os resultados foram expressos em ${ }^{\circ}$ Brix. b) cor: determinada com colorímetro (Minolta), determinando-se os valores de $\mathrm{L} \mathrm{a}^{*} \mathrm{~b}^{*} \mathrm{e}$ calculando-se o índice de cor (IC) através da fórmula $\mathrm{IC}=1000 \times \mathrm{xa} / \mathrm{Lxb}^{*}$ (Mazzuz, 1996). As leituras foram realizadas diretamente sobre o produto minimamente processado. c) perda de massa: através de pesagem direta. d) taxa respiratória: $180 \mathrm{~g}$ de beterraba minimamente processada foram colocadas em frascos de vidro com capacidade 600 $\mathrm{mL}$, sendo fechados hermeticamente durante 1 hora a $5^{\circ} \mathrm{C}$. Na tampa dos fras$\cos$ foi colocado um septo de silicone através do qual foi retirada uma alíquota da atmosfera interna dos frascos $(2 \mathrm{~mL})$ e medida a taxa respiratória em um analisador de gases PBI Dansensor 9900. Os resultados expressos em \%
$\mathrm{CO}_{2}$ foram utilizados para cálculo da taxa respiratória levado-se em consideração o volume do frasco, a massa da beterraba e o tempo em que o frasco permaneceu fechado. d) teores de betacianina e betaxantina: a metodologia utilizada foi adaptada de Nilson (1970). Duas gramas de cada amostra previamente congelada foram maceradas com $5 \mathrm{~mL}$ de água destilada. A solução foi colocada em tubetes e centrifugadas em centrífuga refrigerada (Sorvall) a $4^{\circ} \mathrm{C}$, rotação de 15.000 rpm, durante 40 minutos. Num tubo de ensaio foram homogenizados $1 \mathrm{~mL}$ do sobrenadante e $24 \mathrm{~mL}$ de água destilada. Foram feitas leituras das amostras a $476 \mathrm{~nm}, 538 \mathrm{~nm}$ e $600 \mathrm{~nm}$. Os cálculos foram feitos através das fórmulas: $x=$ 1,095 (a-c), $y=b-z-x / 3,1$ e $z=a-x$, sendo $\mathrm{a}=$ leitura da amostra $(538 \mathrm{~nm}) ; \mathrm{b}=$ leitura da amostra (476 nm); c= leitura da amostra $(600 \mathrm{~nm}) ; \mathrm{x}=$ absorção de betacianina; $y=$ absorção de betaxantina; $z=$ absorção de impurezas. e) avaliação sensorial (aparência global): foi realizada por uma equipe de 5 analisadores treinados utilizando uma escala de notas adaptada de Peryam \& Girarddot (1952), onde $9=$ excelente; 7 = bom; 5 = regular; 3 = ruim; $1=$ péssimo. A descrição das notas utilizada foi $9=$ beterraba com aspecto de frescor e ausência de esbraquiçamento; $7=$ beterraba com aspecto de frescor, porém com leve esbraquiçamento; 5 = beterraba com pouco aspecto de frescor e moderado esbranquiçamento; 3 = beterraba sem aspecto de frescor, elevado esbraquiçamento; 1 = beterraba totalmente desidratada e esbranquiçada. A nota 5 foi considerada como limite de comercialização.

O delineamento experimental foi inteiramente ao acaso em esquema fatorial 3x6 (3 tipos de corte e 6 períodos de avaliação). Utilizaram-se 4 repetições com aproximadamente $180 \mathrm{~g}$ de raízes minimamente processadas. Os resultados das análises fisico-químicas foram submetidos à análise do desvio padrão, onde as diferenças entre dois tratamentos maior que a soma de dois desvios padrões foram consideradas significativas $(\mathrm{P}<0,05)$ (Moretti et al., 2002). Para a análise sensorial os resultados foram submetidos à análise de variância pelo teste $\mathrm{F}$ e comparação das médias pelo Teste de Tukey (5\%).

\section{RESULTADOS E DISCUSSÃO}

O teor de sólidos solúveis totais foi significativamente maior em beterraba minimamente processada com espessura de corte de $8 \mathrm{~mm}$, tendo variado de 4 a $5^{\circ}$ Brix ao longo do armazenamento (Figura 1a). Para os cortes com 2 e 5 $\mathrm{mm}$ de espessura esta variação foi de 2,5 a $3,5^{\circ}$ Brix. Estas diferenças podem ser creditadas à maior perda da compartimentação celular provocada pelos cortes de menor espessura. Segundo Brecht (1995), esta perda de compartimentação aumenta o extravazamento de solutos celulares.

Para o índice de cor (IC), houve redução na coloração característica do produto durante o armazenamento, sem ter sido verificada diferença entre os tratamentos (Figura 1b). Segundo Mazzuz (1996), o IC varia de $-20 \mathrm{a}+20$, sendo que quanto mais positivo, mais intenso é o vermelho. Assim, valores decrescentes do IC ao longo do armazenamento significaram perda da intensidade da coloração vermelha típica da beterraba.

Quanto ao teor de betacianina, não houve diferença significativa entre os tratamentos no decorrer dos dias de armazenamento (Figura 1c). Os teores de betacianina ficaram em valores pró-

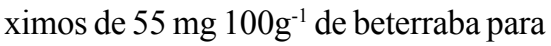
as beterrabas minimamente processadas de todos os tratamentos. O teor de betacianina varia em função da cultivar de beterraba (Nilson, 1973). Para beterrabas intactas os teores de betacianina encontrados foram 45-85, 130-200 e 130-210 mg $100 \mathrm{~g}^{-1}$ de beterrabas para as variedades Banco WW, Boltardy e Rubra, respectivamente.

Os pigmentos de betalaínas são mais solúveis em água do que em álcool (Nilson, 1970). No caso da beterraba minimamente processada os processos de sanitização e enxague, favorecem uma maior perda destes pigmentos devido ao contato da superfície das raízes com a água.

O teor de betaxantina não diferiu significativamente entre os tratamentos durante todo o período de 
armazenamento. O teor de betaxantina obtido em beterraba minimamente processada, submetida a diferentes tipos de cortes, foi próximo de $35 \mathrm{mg} 100 \mathrm{~g}^{-1} \mathrm{de}$ beterraba durante o decorrer do armazenamento (Figura 1d). Nilson (1973) verificou que os teores de betaxantina presentes em diferentes cultivares de beterrabas intactas foram de 20-60, 60-130 e 60-140 mg $100 \mathrm{~g}^{-1}$ de beterraba para as variedades Banco WW, Boltardy e Rubra, respectivamente.

Sapers \& Hornstein (1979) verificaram grande diferença no conteúdo de betacianina e betaxantina nas variedades de beterraba de mesa. Diferenças também ocorrem dentro da cultivar, sendo algumas mais variáveis que outras.

De maneira geral, nota-se uma estabilização nos teores de betacianina e de betaxantina a partir do $2^{\circ}$ dia de armazenamento (Figuras 1c e d) das raízes minimamente processadas. Estes dados são discordantes daqueles obtidos por Osornio \& Chaves (1998), os quais verificaram em beterraba ralada e armazenada a $0^{\circ} \mathrm{C}$ que o teor de betalaína decresceu aproximadamente 40-50\% depois de 7 dias.

Não houve diferença significativa na atividade respiratória da beterraba minimamente processada, submetida a diferentes espessuras de corte, durante o período de armazenamento. Entretanto, no $2^{\circ}$ dia de armazenamento, observouse um pico em valores próximos de 130 $\mathrm{mL} \mathrm{CO}_{2} \mathrm{~kg}^{-1} \mathrm{~h}^{-1}$. Após esse período houve redução e -estabilização em valores próximos de $25 \mathrm{~mL} \mathrm{CO} \mathrm{kg}^{-1} \mathrm{~h}^{-1}$ para todos os tratamentos (Figura 2). Resultados similares foram obtidos por Osornio \& Chaves (1998), em beterrabas raladas e armazenadas a $0^{\circ} \mathrm{C}$.

$\mathrm{O}$ pico respiratório observado em beterraba minimamente processada advém do estresse provocado pelo corte. Este estresse provoca perda da compartimentação celular e com isto os substratos do metabolismo respiratório entram em maior contato com os complexos enzimáticos resultando em aumento da taxa respiratória. A redução subseqüente na taxa respiratória da beterraba minimamente processada do controle (a partir do $4^{\circ}$ dia) se deve provavelmente à auto-regulação da atividade respiratória do tecido devido à gran-

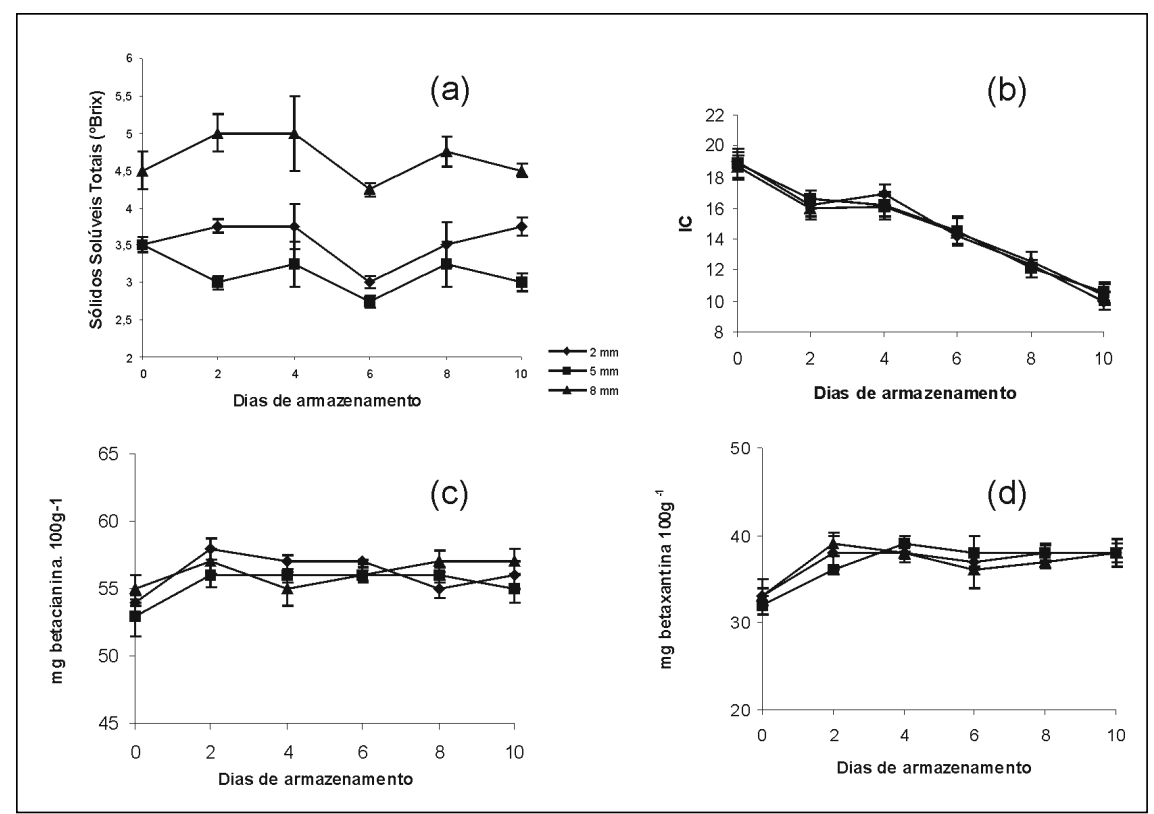

Figura 1. Teor de sólidos solúveis totais (a), índice de cor (b), teor de betacianina(c) e teor de betaxantina (d) em beterraba minimamente processada submetida a diferentes espessuras de corte e armazenadas a $5 \pm 1{ }^{\circ} \mathrm{C}$ e $85 \pm 5 \%$ UR. Barras verticais indicam o desvio padrão da média. Piracicaba, ESALQ, 2002.

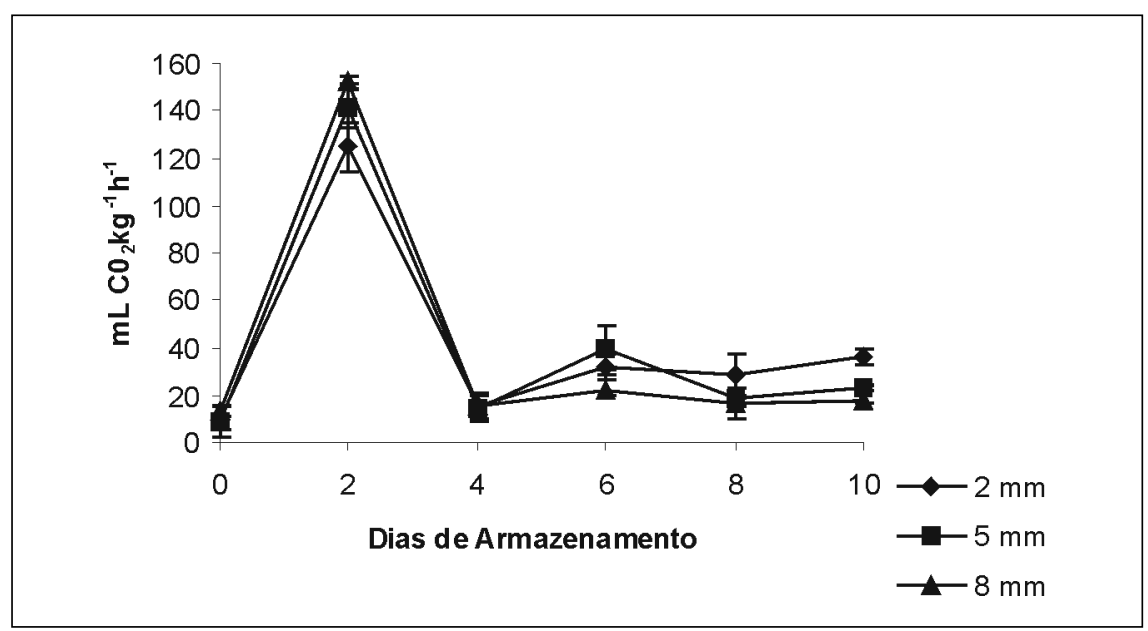

Figura 2. Taxa respiratória de beterraba minimamente processada submetida a diferentes espessuras de corte e armazenadas a $5 \pm 1^{\circ} \mathrm{C}$ e $85 \pm 5 \%$ UR. Barras verticais representam o desvio padrão da média. Piracicaba, ESALQ, 2002.

de produção de ATP (Purvis, 1997). É possível também que esta redução da taxa respiratória ocorra pelo fato dos substratos respiratórios pararem de reagir com as enzimas presentes nas células da superfície de corte. Portanto, a taxa respiratória observada a partir do $4^{\text {o }}$ dia é provavelmente resultante das células localizadas abaixo da superfície injuriada pelo corte.

A injúria mecânica causada pelo corte ou descascamento é um dos maiores obstáculos para a conservação dos produtos minimamente processados, sendo que a taxa respiratória destes produtos é cerca de 3 a 5 vezes maior do que órgãos intactos (Chitarra, 1998). Chervin et al. (1992) observaram que a taxa respiratória de cenoura processada é o dobro da taxa de cenoura inteira nas primeiras quatros horas após o processamento ou até cinco vezes maior após 30-40 horas. Assim, torna-se imprescindível a manutenção do produto 
Tabela 1. Aparência global em beterraba minimamente processada submetida a diferentes espessuras de corte e armazenadas a $5 \pm 1{ }^{\circ} \mathrm{C}$ e $85 \pm 5 \%$ UR ${ }^{1}$. Piracicaba, ESALQ, 2002. $\mathrm{CV}(\%): 26,92$

\begin{tabular}{lcccccc}
\hline \multirow{2}{*}{$\begin{array}{l}\text { Espessura de } \\
\text { corte }\end{array}$} & \multicolumn{7}{c}{ Dias de armazenamento } \\
\cline { 2 - 7 } & $\mathbf{0}$ & $\mathbf{2}$ & $\mathbf{4}$ & $\mathbf{6}$ & $\mathbf{8}$ & $\mathbf{1 0}$ \\
\hline $2 \mathrm{~mm}$ & $9 \mathrm{a}$ & $7 \mathrm{a}$ & $7 \mathrm{a}$ & $5 \mathrm{a}$ & $3 \mathrm{a}$ & $1 \mathrm{~b}$ \\
$5 \mathrm{~mm}$ & $9 \mathrm{a}$ & $7 \mathrm{a}$ & $5 \mathrm{~b}$ & $5 \mathrm{a}$ & $1 \mathrm{~b}$ & $1 \mathrm{~b}$ \\
$8 \mathrm{~mm}$ & $9 \mathrm{a}$ & $7 \mathrm{a}$ & $5 \mathrm{~b}$ & $5 \mathrm{a}$ & $1 \mathrm{~b}$ & $1 \mathrm{~b}$ \\
\hline Médias & $9,00 \mathrm{~A}$ & $7,00 \mathrm{~B}$ & $5,67 \mathrm{C}$ & $5,00 \mathrm{C}$ & $1,67 \mathrm{D}$ & $1,00 \mathrm{D}$ \\
\hline
\end{tabular}

${ }^{1}$ Médias seguidas de mesma letra minúscula na coluna e maiúscula na linha não diferem significativamente entre si, pelo teste de Tukey ao nível de $5 \%$ de probabilidade.

${ }^{2}$ Notas: $9=$ excelente; $7=$ bom; $5=$ regular; $3=$ ruim; $1=$ péssimo.

em baixa temperatura, desde o preparo até a comercialização, visando reduzir a respiração e preservar a qualidade e a vida de prateleira do produto pré-processado.

Para a variável aparência global não foi verificada diferença entre os tratamentos até o segundo dia de armazenamento, sendo que no sexto dia todas as repetições apresentavam-se no limite para a comercialização (Tabela 1).

$\mathrm{O}$ tecido esbranquiçado que se forma na superfície de cenoura minimamente processada, denominada "white blush" por alguns pesquisadores, torna o produto com aparência envelhecida e não atraente. Fato semelhante ocorre com a beterraba minimamente processada. Enquanto para alguns grupos de pesquisadores o esbranquiçamento é resultado da desidratação das células superficiais, devido aos danos causados pelo processamento (Tatsumi et al., 1993; Avena-Bustillos et al., 1994), para outros é devido à formação de lignina na superfície dos cortes (Bolin \& Huxsoll, 1991). Para um terceiro grupo, o esbranquiçamento é causado pela combinação dos dois processos, a desidratação e a formação de lignina (Cisneros-Zevallos et al., 1995). A desidratação se reflete em uma mudança de cor reversível que é tanto mais acentuada quanto maior a perda de água, enquanto a ativação de metabolismo fenólico e a produção de lignina resultam em uma mudança de cor irreversível (Izumi et al., 1996). No presente trabalho houve perda de água do produto préprocessado, entretanto devido ao fato do filme de PVC oferecer uma barreira contra a saída de vapor de água do interior da embalagem, os valores encontrados foram próximos a $0,0 \%$. Além disso, a alta umidade relativa no interior da câmara de armazenamento favoreceu esta perda mínima a partir da embalagem.

Como se observou pelos resultados obtidos, ocorreu uma redução gradativa na coloração das raízes durante o armazenamento para todos os tratamentos. A redução na intensidade de coloração, aparentemente, não se deve a alteração nos teores de pigmentos, já que estes mantiveram-se constantes durante o armazenamento. Acredita-se que esta redução seja devido ao fato de que a leitura da cor foi realizada superficialmente, onde com o decorrer do período de armazenamento, observou-se desidratação e esbranquiçamento, o que reduz a intensidade da cor vermelha na superfície do corte. Os teores de sólidos solúveis totais variaram para todos os tipos de corte. No entanto estas diferenças não foram verificadas na taxa respiratória, no teor de betacianina e de betaxantina no decorrer dos dias de armazenamento. Portanto, conclui-se que a espessura de corte não influencia na qualidade da beterraba minimamente processada. Também pode-se inferir que beterraba minimamente processada mantém boa qualidade por até 6 dias de armazenamento a $5^{\circ} \mathrm{C}$.

\section{AGRADECIMENTOS}

À FAPESP pelo suporte financeiro, processo $n^{\circ} 01 / 00750-2$.

\section{LITERATURA CITADA}

AVENA-BUSTILLOS, R.J.; CISNEROSZEVALLOS, L.A.; KROCHTA, J.M.; SALTVEIT, M.E. Application of casein-lipid edible film emulsions to reduce white bush on minimally processed carrots. Postharvest Biology and Technology, v. 4, n. 4, p. 319-329, 1994.

BRECHT, J.K. Physiology of lightly processed fruits and vegetables. HortScience, v. 30, n. 1, p. 18-22, 1995.

BOLIN, H.R.; HUXSOLL, C.C. Control of minimally processed carrot (Dacus carota) surface discoloration caused by abrasion peeling. Journal of Food Science, v. 56, n. 2, p. 416-418, 1991.

BURNS, J.L. Lightly processed fruits and vegetables: Introduction to the Colloquium. HortScience, v. 30, n. 1, p. 14-17, 1995.

CHERVIN, C.; TRIANTAPHYLIDES, C.; LIBERT, M.F.; SIADOUS, R.; BOISSEAU, P. Reduction of wound induced respiration and ethylene production in carrot root tissues by gamma irradiation. Postharvest Biology and Technology, v. 2, n. 1, p. 7-17, 1992.

CHITARRA, M.I.F. Processamento Mínimo de Frutos e Hortaliças. Viçosa: Centro de Produções Técnicas, 1998. 88 p.

CISNEROS-ZEVALLOS, L.;SALVEIT, M.E.; KROCHTA, J.M. Mechanism of surface white discoloration of peeled carrots during storage. Journal of Food Science, v. 60, n. 2, p. 320-323, 1995.

FENENA, O.R. Quimica de los alimentos. $2^{\circ} \mathrm{ed}$ Zaragoza: Acribia, 1995. 586 p.

IZUMI, H.; WATADA, A.E.; KO, N.P.; DOUGLAS, W. Controlled atmosphere storage of carrots slices, sticks and shreds. Postharvest Biology and Technology, v. 9, n. 2, p. 165-172, 1996.

MAZZUZ, C.F. Calidad de frutos citricos: manual para sugestion desde la recoleccion hasta la expedicion. Barcelona: Edicionas de Horticultura, 1996. 202 p.

MORETTI, C. L.; MAROUELLI, W.A.; SILVA, W. L.C. Respiratory activity and browning of minimally processed sweet potatoes. Horticultura Brasileira, v. 20, p. 497-500, 2002.

NILSON, T. The pigment content in beetroot with regard to cultivar, growth, development and growing conditions. Swedish Journal agricultural Research, v. 3, n. 4, p. 187-200, 1973.

NILSON, T. Studies into the Pigments in Beetroot (Beta vulgaris L. ssp. vulgaris var. rubra L.). Lantbrukhogskolans Annaler, v. 36, p. 179-219, 1970. OSORNIO, M.M.L.; CHAVES, A.R. Quality changes in stored raw grated beetroots as affected by temperature and packaging film. Journal of Food Science, v. 63, n. 2, p. 27-330, 1998.

PERYAM, D.R.; GIRARDDOT, N.F. Advanteced taste method. Food Engeneiring, v. 24, p. 58-61, 1952. PURVIS, A.C. The role of adaptive enzymes in carbohydrates oxidation by stressed and senescing plant tissues. HortScience, v. 32, n. 7, p. 1165168, 1997.

SAPERS, M.G.; HORNSTEIN, J.S. Varietal differences in colorant properties and stability of red beet pigments. Journal of Food Science, v. 44, p. $1245,1979$.

TATSUMI,Y.; WATADA, A.E.; LING, P.P. Sodium chlorine treatment or waterjet slicing effects on white tissue development on carrot sticks. Journal of Food Science, v. 58, n. 6, p. 1390-1392, 1993. 